\title{
Outcome of early surgery after coronary angioplasty
}

\author{
MICHAEL S NORELL, JOHN LYONS, CLIVE LAYTON, RAPHAEL BALCON \\ From the Cardiac Department, London Chest Hospital, London
}

SUMMARY Nineteen of 69 patients undergoing coronary angioplasty required immediate coronary surgery after the procedure. Six of these operations were planned as a result of angioplasty that failed without producing any complication. The remaining 13 cases were operated upon because complications occurred during angioplasty. These were coronary artery dissection in four, occlusion in five, continuing severe spasm in two, tamponade in one, and in one other detachment of a guidewire tip. In these 13 cases the vessel in which angioplasty had been attempted was the left anterior descending coronary artery in eight, the right in four, and the circumflex artery in one. This distribution was no different from that in the 56 patients without complications.

There was one early postoperative death due to extensive anterior myocardial infarction, and there was electrocardiographic evidence of new infarction in three other patients. A mean of 16 months postoperatively, 16 of the 18 surviving patients had no cardiac symptoms, while angina had improved in the remaining two. Sixteen of the 18 patients had nuclear left ventricular angiography after a mean of 27 months. When the results of this investigation were compared with the left ventricular cineangiograms performed before angioplasty was attempted only two patients showed evidence of a new left ventricular wall motion abnormality.

Prompt operation after complications of angioplasty is usually successful with good symptomatic relief and without left ventricular damage. The incidence of complications requiring operation, however, was high in this group of patients, most of whom had single vessel coronary artery disease.

Coronary angioplasty is increasingly used in selected patients with coronary artery disease. Complications occurring during the procedure, however, result in the need for emergency surgery in approximately $6 \%$ of cases. ${ }^{1}$ This paper reviews our experience of the immediate and long term outcome of urgent surgery after angioplasty.

\section{Patients and methods}

All patients undergoing coronary angioplasty had at least moderately severe angina despite full medical treatment, and they were therefore selected to have surgery if angioplasty was not successful.

Left ventricular cineangiography was performed in the $30^{\circ}$ right anterior oblique projection, and nor-

Requests for reprints to Dr M Norell, Cardiac Department, London Chest Hospital, Bonner Road, E2 9JX.

Accepted for publication 8 October 1985 mal left ventricular wall motion was demonstrated in all but four patients. The ejection fraction was measured by planimetry of the end systolic and end diastolic frames (mean ejection fraction $58 \%$, range $20-72 \%$ ).

Before angioplasty was attempted, all patients were given premedication with oral nitrates, nifedipine, and dipyridamole. In all cases a surgical team was aware that an angioplasty was being undertaken. The procedure was scheduled such that in the event of a complication occurring one of two operating theatres would be available for emergency surgery.

\section{FOLLOW UP}

The frequency of myocardial infarction after surgery was determined on the basis of the following electrocardiographic criteria: new $Q$ waves, loss of $R$ wave, and new bundle branch block. The average duration of follow up was 16 months (range 1-45 
months) at which time any cardiac symptoms were noted.

Nuclear left ventricular angiograms were obtained a mean of 27 months after surgery (range 2-54 months). A dose of $0.03 \mathrm{ml} / \mathrm{kg}$ body weight of Amerscan stannous agent was injected intravenously. After 30 minutes $20 \mathrm{mCi}$ of $99 \mathrm{~m}$ technetium pertechnetate was injected into an arm vein. After a further five minutes the patient was scanned while supine in a 45 left anterior oblique position with a large field Siemens gamma camera. The patients performed symptom limited bicycle exercise in a supine position. Gated acquisition took place during the three minutes of the final stage reached.

Left ventricular wall motion analysis was reported by an independent observer who was unaware of the patients' clinical details. We used Student's paired $t$ test for statistical analysis.

\section{Results}

Nineteen $\left(27^{\circ}{ }^{\circ}\right)$ of the 69 consecutive patients undergoing angioplasty required urgent coronary artery surgery (Table). There were 11 men and eight women with a mean age of 55 years (range 47-73 years). All had at least moderately severe anging despite appropriate medical treatment, with 11 hav ing had at least one previous episode of angina atrest. No patient had sustained a recent myocardiat infarction and in all cases the angioplasty was per formed electively. Fifteen patients had single vesse coronary artery disease defined as a lesion producingat least $70^{\circ}{ }^{\circ}$ luminal narrowing in one major coro nary artery. This affected the left anterio descending artery in 11 , the right in three, and the circumflex coronary artery in one patient. Fou $\vec{P}$ patients had two vessel disease. All of them had righ $\vec{t}$ coronary artery disease, three with additional lefon anterior descending artery disease and one witt? circumflex artery disease. In three of these fouer patients angioplasty of only one ressel waks attempted, while in one a double procedure waస attempted.

\section{INDICATIONS FOR SURGERY}

In six patients the stenosis could not be crossed with the dilatating balloon catheter, no complication occurred, and they proceeded to surgery. In ninछ others in whom the lesion could not be crossed ange the remaining four in whom the stenosis had beer crossed a complication necessitated urgent surgery.

Table Patients who required early coronary artery surgery after angioplasty

\begin{tabular}{|c|c|c|c|c|c|c|c|c|c|c|c|c|c|}
\hline \multirow{2}{*}{$\begin{array}{l}\text { Casie' } \\
\text { Nis }\end{array}$} & \multirow{2}{*}{$A g c^{\prime}$} & \multirow[t]{2}{*}{ Sex } & \multirow{2}{*}{$\begin{array}{l}\text { Angina } \\
\text { grade }\end{array}$} & \multirow{2}{*}{$\begin{array}{l}\text { Stenosis } \\
\text { site }\end{array}$} & \multirow{2}{*}{$\begin{array}{l}I . V \\
I: I \\
" \prime\end{array}$} & \multirow{2}{*}{$\begin{array}{l}\text { Wall motion } \\
\text { abnormality }\end{array}$} & \multirow[t]{2}{*}{ Complication } & \multirow{2}{*}{$\begin{array}{l}\text { Time to } \\
\text { bypass } \\
\text { (min) }\end{array}$} & \multirow[t]{2}{*}{ Grafts applied } & \multicolumn{4}{|c|}{ Postoperative data } \\
\hline & & & & & & & & & & $E C G$ & $\begin{array}{l}\text { Angina } \\
\text { grade }\end{array}$ & $\begin{array}{l}\text { LVEF } \\
\text { lexeritic }\end{array}$ & 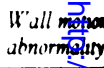 \\
\hline 1 & 56 & $\mathrm{~F}$ & 3 & I.AD & 68 & Apical & - & - & LAD & - & 0 & 53 & Apical \\
\hline 2 & 57 & $M$ & 4 & RCA & 70 & - & - & - & RCA & - & 0 & $58(67$ & - Q \\
\hline 3 & 62 & $\mathrm{~F}$ & 3 & $\begin{array}{r}\text { I.AD, } \\
\text { RCA }\end{array}$ & 51 & Anterior & - & - & LAD, RCA & 一 & 0 & $37(30)$ & Anterie \\
\hline 4 & 54 & $M$ & 4 & LAD & 39 & Apical & - & - & LAD & - & 0 & $35(39)$ & Apical \\
\hline 5 & 57 & $\mathrm{~F}$ & 3 & LAD & 50 & - & - & - & L.AD & - & 0 & $45(55$ & - \\
\hline 0 & 71 & $\mathrm{~F}$ & 4 & $\begin{array}{l}\text { LAD, } \\
\text { RCA }\end{array}$ & 57 & - & - & - & LAD, RCA & - & 0 & Unavailable & \\
\hline 7 & 66 & $M$ & 4 & LAD & 60 & - & LAD occlusion & - & LAD diagonal & $\begin{array}{l}\text { Anterior } \\
Q \text { waves }\end{array}$ & 0 & 31 & Anteries \\
\hline 8 & 73 & $\mathrm{~F}$ & 3 & I.AI) & 69 & - & I. Cx dissected & 180 & LAD, LCx & $\begin{array}{l}\text { Bundle } \\
\text { branch } \\
\text { block }\end{array}$ & 0 & $58(67)$ & -- 吾. \\
\hline 9 & 56 & $M$ & 4 & $\begin{array}{l}\text { RCA, } \\
\text { ICCX }\end{array}$ & 20 & Anterior & RC:A dissected & 150 & RCA, I.C $x$ & - & 0 & $39(43$ & Anteriog \\
\hline 10 & 47 & $M$ & 4 & I.AD & 71 & - & I.MS perforated & 95 & I.AD, I.Cx & - & 0 & $61(68)$ & $-\quad 0$ \\
\hline 11 & 56 & $M$ & 3 & LAD & 47 & - & LAD occluded & - & LAD, LCx & 一 & 1 & 54 & - \\
\hline 12 & $5+$ & $M$ & 4 & I.AD & 49 & - & I.AI) spasm & - & I.AD & - & 2 & $62(50)$ & - \\
\hline 13 & 62 & M & 4 & I.AD & 55 & - & I.AD occluded & 240 & I.AD, RCA & 一 & 0 & $48(58)$ & $\underset{\gamma}{\sigma}$ \\
\hline 1.4 & 49 & M & 3 & I.CX & 6() & - & LMS dissected & 60 & I.AD, I.Cx & $\begin{array}{l}\text { Anterior } \\
\text { Q waves }\end{array}$ & & 1)icd & 을 \\
\hline 15 & 5() & M & 3 & LAD & 70 & - & I.AD occluded & 88 & LAD & - & 0 & $60(61)$ & $-\mathscr{D}$ \\
\hline 16 & 54 & $F^{*}$ & 4 & $\begin{array}{l}\text { I.AD } \\
\text { RC.A* }\end{array}$ & 71 & - & RC:A dissected & 60 & I.AD, RCA & $\begin{array}{l}\text { Reduced } \\
\text { inferior } \\
\mathrm{R} \text { wave }\end{array}$ & 0 & $28(24)$ & Apical \\
\hline 17 & 55 & $\mathrm{~F}$ & 4 & RC:A & 72 & - & RCA occluded & 150 & I.AD, RCA & - & 0 & 56 & - \\
\hline 18 & 54 & $M$ & 3 & RC.A & 61 & - & RC.A spasm & 60 & RCA & - & 0 & Unavailable & $\stackrel{\rho}{\Phi}$ \\
\hline 19 & 60 & $F$ & 4 & I.AD & 71 & - & $\begin{array}{l}\text { Guidewire tip } \\
\text { detached }\end{array}$ & 60 & $\begin{array}{l}\text { L.AD diagonal } \\
\text { LCCx }\end{array}$ & 一 & 0 & $58(45)$ & $\frac{\mathbb{D}}{\sigma}$ \\
\hline
\end{tabular}

*Vessel attempted.

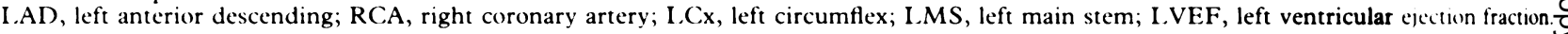




\section{COMPLICATIONS OF ANGIOPLASTY}

Coronary artery dissection occurred in four patients. The right coronary artery was dissected in two and a lateral circumflex in another. These patients developed severe chest pain and ST segment elevation. The left main stem was dissected in another patient who developed a profound bradycardia and became hypotensive.

The coronary artery became occluded without apparent dissection in five patients (in four in an attempt to dilatate a left anterior descending artery lesion and in one a right coronary artery lesion). All five developed severe pain and ST segment elevation and therefore went on to surgery. In two patients coronary artery spasm was assumed to have occurred after initially successful dilatation of a left anterior descending lesion in one and of a right coronary stenosis in another patient. In both cases there had been transient occlusion after dilatation which had temporarily reopened after intracoronary nitrates. The subsequent occlusion had been persistent, and surgery was undertaken because of pain and ST segment elevation.

One patient developed pericardial tamponade. He had become markedly hypotensive after an unsuccessful attempt to cross a stenosis of the left anterior descending coronary artery and at emergency surgery it was apparent that the left main stem had been perforated. In another patient with a stenosis of the left anterior descending artery the fixed guidewire tip of the balloon catheter became detached and lodged in the main circumflex artery. Though there was no clinical deterioration, it was felt that surgery should be performed.

In the 13 cases with complications of angioplasty the stenosis that we attempted to cross was in the left anterior descending artery in eight $(62 \%)$, the right coronary artery in four $(31 \%)$, and the circumflex artery in one $(7 \%)$. This frequency resembled that in 56 patients who had undergone attempted angioplasty without the occurrence of a complication.

While emergency surgery was being arranged the patients received intravenous nitrates, sublingual nifedipine, and diamorphine. Intra-aortic counterpulsation balloon pumps were not inserted. One patient (case 16) developed ventricular fibrillation requiring direct current defibrillation and another (case 14) required external cardiac massage until cardiopulmonary bypass was established.

\section{SURGERY}

The interval (mean 114, range 60-240 minutes) from the recognition of a complication at angioplasty to the patient being put on cardiopulmonary bypass was known in 10 of the 13 complicated cases.

Seven of the 15 patients with single vessel disease received a single vein graft. Seven of the other eight patients with single vessel disease had two vein grafts. In three this was for mild disease in another vessel while in one the lesion was proximal to a diagonal vessel which was therefore also grafted. The remaining three patients with single vessel disease received additional grafts as a direct result of the angioplasty. In one a lateral circumflex artery had been dissected during attempt to dilatate a lesion of the left anterior descending artery. Two patients had sustained damage to the left main stem and both required left anterior descending and circumflex grafting.

One patient (case 19) with stenosis of the left anterior descending artery required three vein grafts. In this case the fixed guidewire tip of the balloon catheter had become detached and lodged in the main circumflex artery. This vessel was explored in an unsuccessful attempt to recover the guidewire tip, and was therefore also grafted in addition to the left anterior descending and diagonal arteries which had been grafted because of a proximal lesion in the left anterior descending artery.

\section{MYOCARDIAL INFARCTION}

There was evidence of new infarction in four patients. One of these (case 14), in whom the left main stem had been dissected, developed an extensive anterior myocardial infarction and was moribund before an emergency operation was performed. He did not survive. The other three patients were also from the group with complications and one of them had occluded left anterior descending artery. The other two had dissection of right and circumflex arteries.

\section{SYMPTOMS}

Sixteen of the 18 surviving patients had no cardiac symptoms at follow up. Angina had improved in the remaining two.

\section{LEFT VENTRICULAR FUNCTION}

Nuclear left ventricular angiography was not performed on two patients. One had an occlusion of the right coronary artery during angioplasty without evidence of infarction, had proceeded to successful operation, and was subsequently symptom free. The other had had no complication at angioplasty and was also symptom free after operation.

In the remaining 16 patients analysis of ejection fraction showed a small but significant reduction in mean ejection fraction at rest $(58 \%$ vs $49 \%$, $\mathrm{p}<0.05$ ). Ejection fraction rose on exercise in five of the eight patients studied.

Analysis of left ventricular wall motion in 16 patients showed that only two had developed new 
segmental abnormalities. Both had had normal left ventricular contraction on their left ventricular cineangiograms before angioplasty but had new anteroapical wall motion abnormalities in the follow up nuclear angiogram. Both had sustained an occlusion of the left anterior descending artery during attempted angioplasty.

\section{Discussion}

The place of urgent coronary artery surgery after complicated angioplasty is unclear. Our experience shows that it is feasible and the frequency of myocardial infarction $(31 \%)$, as judged by electrocardiographic changes, suggests that this is not an inevitable sequel of complicated angioplasty. These data resemble those of the National Heart, Lung and Blood Institute Registry. ${ }^{1}$ This reported that $26 \%$ of patients requiring urgent surgery developed $Q$ wave infarction (52 of 202 patients) and similar results have been reported by others. ${ }^{2}$

There is evidence that prompt revascularisation within two to three hours of the onset of myocardial ischaemia may limit the extent of infarction. ${ }^{3}$ This resembles the circumstances in the patients with complications, most of whom were on cardiopulmonary bypass within two hours. Other factors which may have contributed to the relatively low frequency of infarction despite coronary artery occlusion, are the presence of collateral flow distal to the damaged artery and the possibility of spontaneous thrombolysis. The reversal of previously persistent coronary artery spasm may have been another factor, as may premedication with calcium antagonists which could have protected a potentially ischaemic myocardium ${ }^{4}$.

The frequency of complications requiring urgent coronary artery surgery during angioplasty in this group is high compared with that reported in other series in which emergency surgery was required by about $6 \%$ of patients. ${ }^{1}$ Our patients were operated on by three individuals who were becoming experienced in angiography and this in part accounts for the high complication rate. Complications such as those described here are often treated by repeat angioplasty rather than by surgery. ${ }^{56}$ Since, however, the duration of myocardial viability is dependent on unknown variables such as the extent of collateral flow, at the time of this study we took the view that once obstruction had occurred it was unlikely that revascularisation could be achieved soon enough by attempting repeat angioplasty. This approach accounts for the high rate of emergency surgery. Subsequent experience, however, has demonstrated that our view was not correct.

Despite the relatively good results of surgery in terms of symptoms and left ventricular function in these patients, morbidity and mortality were high in a group in which most patients had only single vessel disease and normal left ventricular function. Our experience emphasises that operators acquiring experience of the technique should only select for angioplasty those patients whose angina on medical treatment is important enough to make them candidates for surgery.

\section{References}

1 Cowley MJ, Dorros G, Kelsey SF, Van Raden M, Detre KM. Emergency coronary bypass surgery after coronary angioplasty: the National Heart, Lung and Blood Institute's percutaneous transluminal coronary angioplasty registry experience. $\mathrm{Am} \mathcal{F}$ Cardiol 1983; 53: $22-6$.

2 Murphy DA, Craver JM, Jones EL, Gruentzig AR, King SB, Hatcher CR. Surgical revascularisation following unsuccessful percutaneous transluminal coronary angioplasty. I Thorac Cardiovasc Surg 1982; 84: 342-8.

3 Reduto LA, Freund GC, Gaeta JM, Smalling RW, Lewis B, Gould KL. Beneficial effects of intracoronary streptokinase on left ventricular salvage and performance. Am Heart $\mathcal{F}$ 1981; 102: 1168-77.

4 Surruys PW, Brand M, Brower RW, Hugenholtz PG. Regional cardioplegia and cardio-protection during transluminal angioplasty, which role for nifedipine? Eur Heart f 1983; 4: 115-21.

5 Hollman J, Gruentzig AR, Douglas JS, King SB, Ischinger T, Meier B. Acute occlusion after percutaneous transluminal coronary angioplasty-a new approach. Circulation 1983; 68: 725-32.

6 Marquis JF, Schwartz L, Aldridge H, Majid P, Henderson M, Matushinsky E. Acute coronary artery occlusion during percutaneous transluminal coronary angioplasty treated by redilation of the occluded segment. $f$ Am Coll Cardiol 1984; 4: 1268-71. 